\title{
Decreased placental oxygenation capacity in pre-eclampsia: clinical application of a novel index of placental function preformed at the time of delivery*
}

\author{
Koji Matsuo ${ }^{1, \star *}$, Andrew M. Malinow ${ }^{1,2}$, \\ Chris R. Harman ${ }^{1}$ and Ahmet A. Baschat ${ }^{1}$ \\ ${ }^{1}$ Department of Obstetrics, Gynecology, and \\ Reproductive Science, University of Maryland School \\ of Medicine, Baltimore, MD, USA \\ 2 Department of Anesthesiology, University of Maryland \\ School of Medicine, Baltimore, MD, USA
}

\begin{abstract}
Objective: We have previously described placental oxygenation capacity as an index of placental function. The aim of this study was to utilize this test to evaluate placental gas exchange capacity in pre-eclampsia and fetal growth restriction (FGR).

Study design: Two nested case-control studies were conducted between: (i) pre-eclamptic appropriate-forgestational-age fetus (AGA) and non-pre-eclamptic AGA; and (ii) pre-eclamptic FGR and non-pre-eclamptic FGR based on gestational age match. Umbilical A-V gas differences were compared between groups.

Results: Pre-eclamptic AGA was associated with smaller $\mathrm{A}-\mathrm{V} \mathrm{pO}_{2}$ and $\mathrm{A}-\mathrm{V} \mathrm{pCO}$ differences compared to non-preeclampsia $\left(A-V \mathrm{pO}_{2}, 7.1 \pm 3.8 \mathrm{~mm} \mathrm{Hg}\right.$ vs. $11.3 \pm 5.9 \mathrm{~mm}$ $\mathrm{Hg}, \mathrm{P}=0.001 ; \mathrm{A}-\mathrm{V} \mathrm{pCO}_{2}, 7.8 \pm 5.7 \mathrm{~mm} \mathrm{Hg}$ vs. $10.7 \pm$ $5.9 \mathrm{~mm} \mathrm{Hg}, \mathrm{P}=0.01$ ). Pre-eclamptic FGR was associated with smaller $\mathrm{A}-\mathrm{V} \mathrm{pO}_{2}$ and $\mathrm{A}-\mathrm{V} \mathrm{pCO}_{2}$ differences compared to non-pre-eclampsia $\left(\mathrm{A}-\mathrm{V} \mathrm{pO}_{2}, 6.6 \pm 3.1 \mathrm{~mm} \mathrm{Hg}\right.$ vs. $10.8 \pm 8.1 \mathrm{~mm} \mathrm{Hg}, \mathrm{P}<0.001 ; 6.7 \pm 4.5 \mathrm{~mm} \mathrm{Hg}$ vs. $10.9 \pm 10.3 \mathrm{~mm} \mathrm{Hg}, \mathrm{P}=0.044)$. Pre-eclamptic FGR also had significantly lower venous $\mathrm{pO}_{2}$ but not arterial $\mathrm{pO}_{2}$ (Venous $\mathrm{pO}_{2}, 20.3 \pm 6.3 \mathrm{~mm} \mathrm{Hg}$ vs. $25.4 \pm 11.9 \mathrm{~mm} \mathrm{Hg}$, $\mathrm{P}=0.003$ ).

${ }^{*}$ The abstract was presented at the $27^{\text {th }}$ Annual Meeting of the Society for Maternal-fetal Medicine (SMFM), February 5-10, 2007, San Francisco, CA (ID Number 0460).

${ }^{\star}$ Corresponding author:

Koji Matsuo, MD

Department of Obstetrics, Gynecology, and

Reproductive Sciences

University of Maryland Medical Center

University of Maryland School of Medicine

22S Greene Street

P.O. Box 290

Baltimore, MD 21201

USA

Tel.: + 1-410-328-5959

Fax: +1-410-328-0279

E-mail: kmats001@umaryland.edu
\end{abstract}

Conclusion: Pre-eclampsia decreases the placental oxygenation capacity as measured by the umbilical arterialvenous oxygen difference.

Keywords: Intrauterine growth restriction; oxygenation; placenta; pre-eclampsia; umbilical cord blood gas.

\section{Introduction}

The placenta is the nutrient and gas exchange organ between mother and fetus. The adequacy of gas exchange is related to maternal placental perfusion and the adequacy of uptake is related to fetal perfusion and ramification of the villous tissue. We have previously described an index of placental function in terms of placental oxygenation capacity (umblical arterial-venous oxygen difference, or $\mathrm{A}-\mathrm{V} \mathrm{pO}_{2}$ difference) [9]. In the study, the placenta had constant oxygenation throughout pregnancy, independent from gestational age, birth weight, duration of labor, and mode of delivery.

Since pre-eclampsia is frequently associated with shallow placentation caused by inadequate trophoblast invasion into the maternal spiral artery $[4,6,7,13]$, it might be a model for abnormalities in the maternal compartment. Fetal growth restriction (FGR) on the other hand is frequently associated with umbilical blood flow abnormalities and decreased oxygen availability [12], and therefore, serves as a model of abnormalities in the fetal compartment.

The aim of the study is to evaluate the impacts of maternal, fetal, and placental dysfunction on placental oxygenation capacity.

\section{Patients and methods}

Nested case-control studies were conducted using arterial and venous umbilical cord blood data recorded as part of a multicenter observational study of growth restricted fetuses. An additional set of patients was ascertained from our prospectively maintained perinatal database. Only singleton pregnancies delivered by pre-labor cesarean delivery were included. Excluded were also patients with fetal anomalies, placental abruption, umbilical cord prolapse, uterine rupture, and bleeding placenta previa.

The abstracted data included presence or absence of preeclampsia, gestational age at delivery, mode of delivery, indication of delivery, anesthesia at delivery, Apgar scores, infant 
weight with birth weight percentile, and the results of umbilical cord arterial and venous blood gasses. Umbilical cord blood gasses include $\mathrm{pH}, \mathrm{pO}_{2}, \mathrm{pCO}_{2}, \mathrm{HCO}_{3}^{-}$, and base excess. The crude $\mathrm{A}-\mathrm{V} \mathrm{pO}_{2}$ and $\mathrm{pCO}_{2}$ differences were calculated and were expressed as absolute values [9]. Pre-eclampsia was defined as a sustained blood pressure $\geq 140 / 90 \mathrm{~mm} \mathrm{Hg}$ with proteinuria $\geq 300 \mathrm{mg}$ from a 24 -h urine collection or $\geq 1+$, after 20 weeks of gestation [16]. FGR was defined as the birth weight below the $10^{\text {th }}$ percentile of gestational age in association with abnormal umbilical artery Doppler index [1].

Two nested studies were conducted between: (i) pre-eclamptic patients with an appropriate-for-gestational-age fetus (AGA) and non-pre-eclamptic AGA; and (ii) pre-eclamptic FGR and non-pre-eclamptic FGR. Patients were matched by gestational age at delivery.

Continuous variables were analyzed by Mann-Whitney $U$-test and mean $\pm S D$ or median with interquartile range, as appropriate. Pearson's correlation analysis and regression analysis with $95 \%$ individual prediction interval were used as appropriate. Two-tailed tests with $\mathrm{P}<0.05$ were considered significant. The statistical significance was determined using Statistical Package for Social Scientists software (SPSS, Inc., version 12.0, Chicago, IL). The study protocol was approved by the Institutional Review Board (IRB) at the University of Maryland School of Medicine.

\section{Results}

Three hundred and seventy-nine patients were evaluated: 138 (36.4\%) of non-pre-eclamptic AGA, 114 (30.1\%) of pre-eclamptic FGR, 80 (21.1\%) of non-pre-eclamptic FGR, and 47 (12.4\%) of pre-eclamptic AGA. Due to these proportions, one-to-two ratio gestational age based match was performed between pre-eclamptic AGA and non-pre-eclamptic AGA (post-hoc analysis).

\section{Pre-eclampsia vs. non-pre-eclampsia in AGA}

Patient characteristics and umbilical cord gas analyses are shown in Table 1. Mean gestational age in both groups was $30.4 \pm 3.6$ weeks. The proportions of type of anesthesia were similar in the two groups (general anesthesia, pre-eclampsia vs. non-pre-eclampsia, $45.2 \%$ vs. $28.6 \%, \mathrm{P}=0.16)$. Umbilical arterial $\mathrm{pO}_{2}$ in pre-eclampsia was similar to non-pre-eclamptics (13.9 $46.7 \mathrm{~mm} \mathrm{Hg}$ vs. $15.3 \pm 6.5 \mathrm{~mm} \mathrm{Hg}, \mathrm{P}=0.29$ ) whereas significantly smaller venous $\mathrm{pO}_{2}$ return was seen in pre-eclampsia compared to non-pre-eclampsia $(21.0 \pm 5.9 \mathrm{~mm} \mathrm{Hg}$ vs. $26.6 \pm 8.1$ $\mathrm{mm} \mathrm{Hg}, \mathrm{P}=0.001)$. Accordingly, oxygenation capacity in pre-eclamptic placenta, the $\mathrm{A}-\mathrm{V} \mathrm{pO}_{2}$ difference, was significantly smaller than in the non-pre-eclamptic placenta: $7.1 \pm 3.8 \mathrm{~mm} \mathrm{Hg}$ vs. $11.3 \pm 5.9 \mathrm{~mm} \mathrm{Hg}, \mathrm{P}=0.001$. Placental oxygen supply was constant during pregnancy (Figure 1). Pre-eclamptic patients showed smaller distribution of oxygenation compared to non-pre-eclampsia. Pre-eclamptic patients also had smaller carbon dioxide

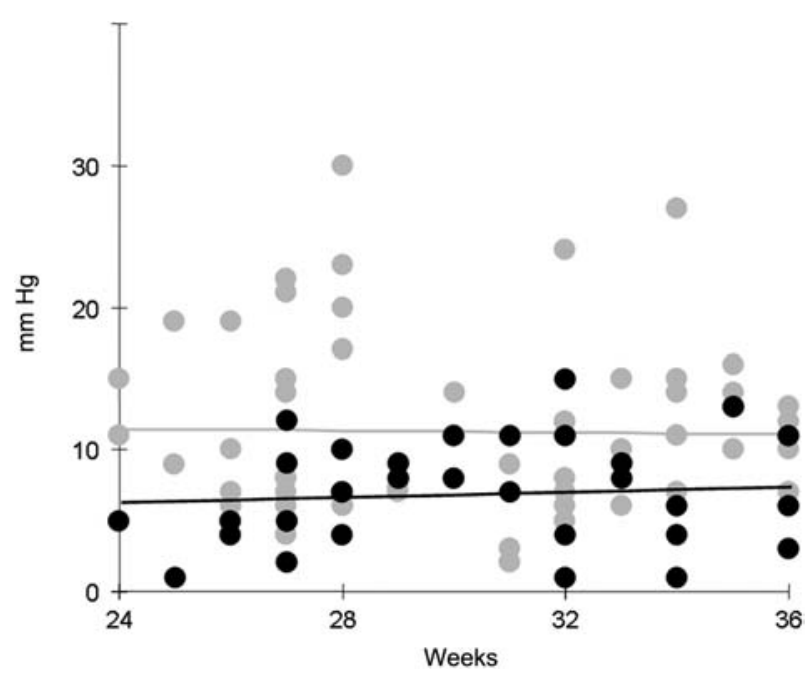

Figure $1 \quad \mathrm{~A}-\mathrm{V} \mathrm{pO}_{2}$ difference in appropriate-for-gestational-age fetus. Black $=$ pre-eclampsia, Gray=non-pre-eclampsia.

Table 1 Umbilical cord gasses analyses in appropriate-for-gestational-age fetus.

\begin{tabular}{|c|c|c|c|}
\hline Subjects & $\begin{array}{l}\text { Pre-eclampsia } \\
\mathrm{n}=33\end{array}$ & $\begin{array}{l}\text { Non-pre-eclampsia } \\
\mathrm{n}=66\end{array}$ & P-value \\
\hline Gestational age (weeks) & $30.4 \pm 3.6$ & $30.4 \pm 3.6$ & 1.0 \\
\hline Birth weight $(\mathrm{g})$ & $1518 \pm 648$ & $1685 \pm 811$ & 0.4 \\
\hline Apgar 1 min & $6(1-9)$ & $6(1-9)$ & 0.68 \\
\hline Apgar $5 \mathrm{~min}$ & $8(2-9)$ & $8(2-9)$ & 0.77 \\
\hline Arterial pH & $7.20 \pm 0.12$ & $7.22 \pm 0.1$ & 0.49 \\
\hline Arterial $\mathrm{pO}_{2}$ & $13.9 \pm 6.7$ & $15.3 \pm 6.5$ & 0.29 \\
\hline Arterial $\mathrm{pCO}_{2}$ & $60.3 \pm 16.7$ & $59.8 \pm 13.6$ & 0.68 \\
\hline Arterial $\mathrm{HCO}_{3}$ & $22.4 \pm 3.8$ & $23.5 \pm 3.9$ & 0.08 \\
\hline Arterial base excess & $-6.0 \pm 4.8$ & $-4.8 \pm 4.4$ & 0.11 \\
\hline Venous pH & $7.24 \pm 0.12$ & $7.29 \pm 0.09$ & 0.03 \\
\hline Venous $\mathrm{pO}_{2}$ & $21.0 \pm 5.9$ & $26.6 \pm 8.1$ & 0.001 \\
\hline Venous $\mathrm{pCO}_{2}$ & $52.5 \pm 15.1$ & $49.1 \pm 12.6$ & 0.29 \\
\hline Venous $\mathrm{HCO}_{3}$ & $22.1 \pm 4.1$ & $23.0 \pm 2.5$ & 0.26 \\
\hline Venous base excess & $-5.0 \pm 5.2$ & $-3.4 \pm 3.2$ & 0.06 \\
\hline $\mathrm{A}-\mathrm{V} \mathrm{pO}_{2}$ difference & $7.1 \pm 3.8$ & $11.3 \pm 5.9$ & 0.001 \\
\hline $\mathrm{A}-\mathrm{V} \mathrm{pCO}_{2}$ difference & $7.8 \pm 5.7$ & $10.7 \pm 5.9$ & 0.01 \\
\hline
\end{tabular}

Mean \pm SD or median (range) is shown. Mann-Whitney $U$-test for all statistic comparisons. 
clearance: $\mathrm{A}-\mathrm{V} \mathrm{pCO}_{2}$ difference, $7.8 \pm 5.7 \mathrm{~mm} \mathrm{Hg}$ vs. $10.7 \pm 5.9 \mathrm{~mm} \mathrm{Hg}, \mathrm{P}=0.01$ (Table 1). Throughout pregnancy, $\mathrm{A}-\mathrm{V} \mathrm{pCO}_{2}$ difference in pre-eclampsia was smaller (Figure 2).

\section{Pre-eclampsia vs. non-pre-eclampsia in FGR}

Placental oxygenation capacity was evaluated between pre-eclamptic FGR and non-pre-eclamptic FGR (Table 2). Mean gestational age in the two groups was $30.2 \pm 3.0$ weeks. The proportions of type of anesthesia were similar in the two groups (general anesthesia, pre-eclampsia vs. non-pre-eclampsia, $34.5 \%$ vs. $42.6 \%, P=0.42$ ). Placental oxygenation capacity in pre-eclamptic FGR was significantly decreased compared to non-pre-eclamptic FGR $(6.6 \pm 3.1 \mathrm{~mm} \mathrm{Hg}$ vs. $11.4 \pm 8.0 \mathrm{~mm} \mathrm{Hg}, \mathrm{P}<0.001)$.

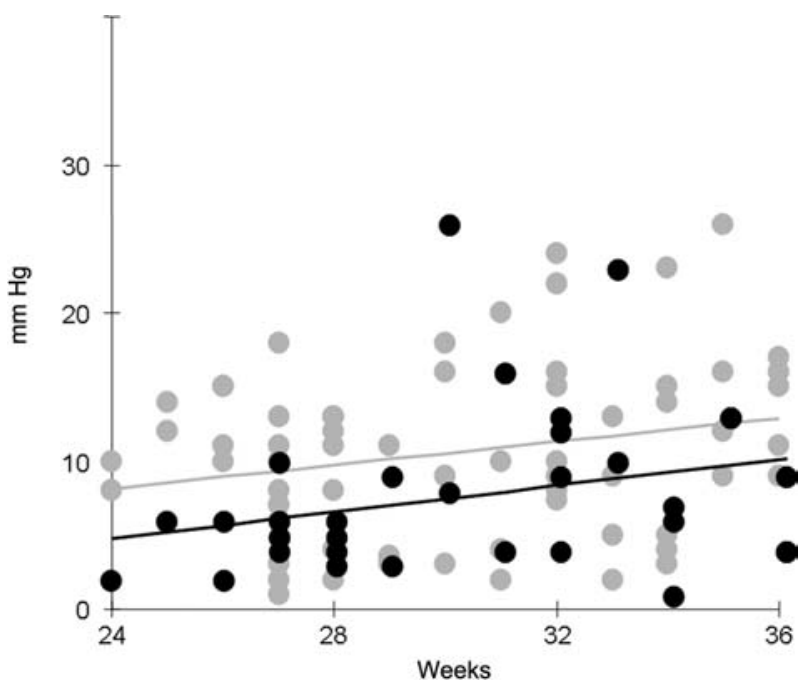

Figure $2 \mathrm{~A}-\mathrm{V} \mathrm{pCO}_{2}$ difference in appropriate-for-gestationalage fetus. Black $=$ pre-eclampsia, Gray=non-pre-eclampsia.
This was supported by significantly smaller oxygenated venous return seen in pre-eclampsia whereas similar arterial oxygen tension were seen in both groups: venous $\mathrm{pO}_{2}, 20.3 \pm 6.3 \mathrm{~mm} \mathrm{Hg}$ vs. $25.4 \pm 11.9 \mathrm{~mm} \mathrm{Hg}, \mathrm{P}=0.003$; arterial $\mathrm{pO}_{2}, 13.7 \pm 5.4 \mathrm{~mm} \mathrm{Hg}$ vs. $14.5 \pm 7.9 \mathrm{~mm} \mathrm{Hg}$ $\mathrm{P}=0.97$. The $\mathrm{A}-\mathrm{V} \mathrm{pCO}_{2}$ difference in pre-eclamptic FGR was smaller than in non-pre-eclamptic women $(6.7 \pm 4.5 \mathrm{~mm} \mathrm{Hg}$ vs. $10.9 \pm 10.3 \mathrm{~mm} \mathrm{Hg}, \mathrm{P}=0.044)$. Placental oxygen supply in FGR was constant during pregnancy (Figure 3). Pre-eclamptic FGR pregnancies showed smaller distribution of oxygenation compared to non-pre-eclamptics.

$\mathrm{A}-\mathrm{V} \mathrm{pO}_{2}$ difference between pre-eclampsia with AGA fetus and pre-eclampsia with FGR fetus appears similar (Figure 4).

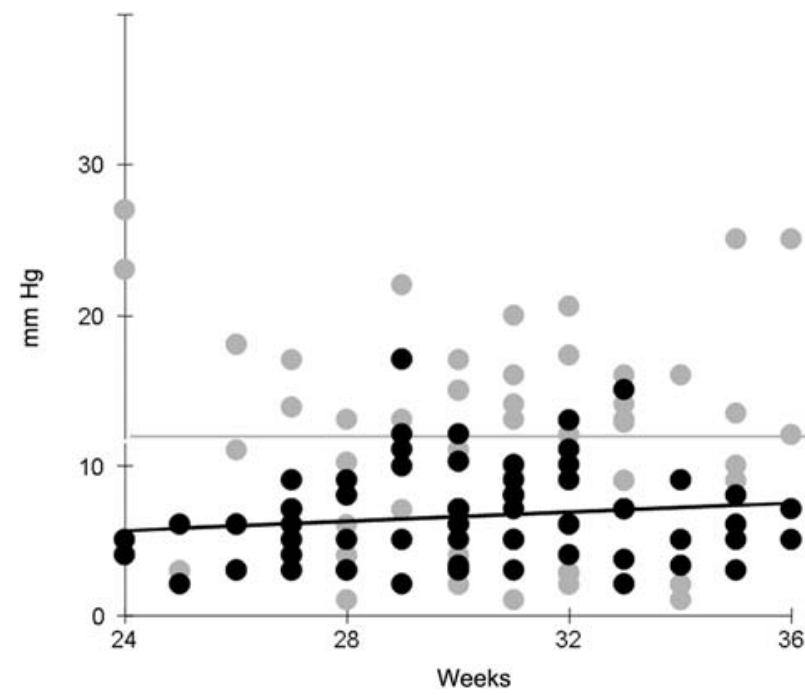

Figure $3 \mathrm{~A}-\mathrm{V} \mathrm{pO}$, difference in fetuses with growth restriction Black $=$ pre-eclampsia, Gray $=$ non-pre-eclampsia.

Table 2 Umbilical cord gasses analyses in intrauterine growth restriction fetus.

\begin{tabular}{lllc}
\hline Subjects & $\begin{array}{l}\text { Pre-eclampsia } \\
\mathrm{n}=67\end{array}$ & $\begin{array}{l}\text { Non-pre-eclampsia } \\
\mathrm{n}=67\end{array}$ & $\begin{array}{c}\text { P-value } \\
\text { Gestational age (weeks) }\end{array}$ \\
Birth weight (g) & $30.2 \pm 3.0$ & $30.2 \pm 3.0$ & 1.0 \\
Apgar 1 min & $989 \pm 360$ & $964 \pm 406$ & 0.44 \\
Apgar 5 min & $5(1-9)$ & $6(1-9)$ & 0.73 \\
Arterial pH & $8(2-9)$ & $8(2-9)$ & 0.82 \\
Arterial $\mathrm{pO}_{2}$ & $7.23 \pm 0.09$ & $7.20 \pm 0.10$ & 0.12 \\
Arterial $\mathrm{pCO}_{2}$ & $13.7 \pm 5.4$ & $14.5 \pm 7.9$ & 0.97 \\
Arterial $\mathrm{HCO}_{3}$ & $57.8 \pm 10.6$ & $60.1 \pm 11.7$ & 0.25 \\
Arterial base excess & $23.3 \pm 3.5$ & $22.1 \pm 3.8$ & 0.044 \\
Venous $\mathrm{pH}$ & $-6.3 \pm 4.8$ & $-4.6 \pm 4.6$ & 0.039 \\
Venous $\mathrm{pO}_{2}$ & $7.27 \pm 0.09$ & $7.26 \pm 0.09$ & 0.49 \\
Venous $\mathrm{pCO}_{2}$ & $20.3 \pm 6.3$ & $25.4 \pm 11.9$ & 0.003 \\
Venous $\mathrm{HCO}_{3}$ & $51.2 \pm 9.8$ & $49.2 \pm 11.9$ & 0.36 \\
Venous base excess & $22.9 \pm 3.6$ & $22.3 \pm 3.0$ & 0.23 \\
$\mathrm{~A}-\mathrm{V} \mathrm{pO}_{2}$ difference & $-4.7 \pm 4.1$ & $-3.8 \pm 4.2$ & 0.27 \\
$\mathrm{~A}-\mathrm{V} \mathrm{pCO}_{2}$ difference & $6.6 \pm 3.1$ & $11.4 \pm 8.0$ & $<0.001$ \\
\hline
\end{tabular}

Mean \pm SD or median (range) is shown. Mann-Whitney $U$-test for all statistic comparisons. 

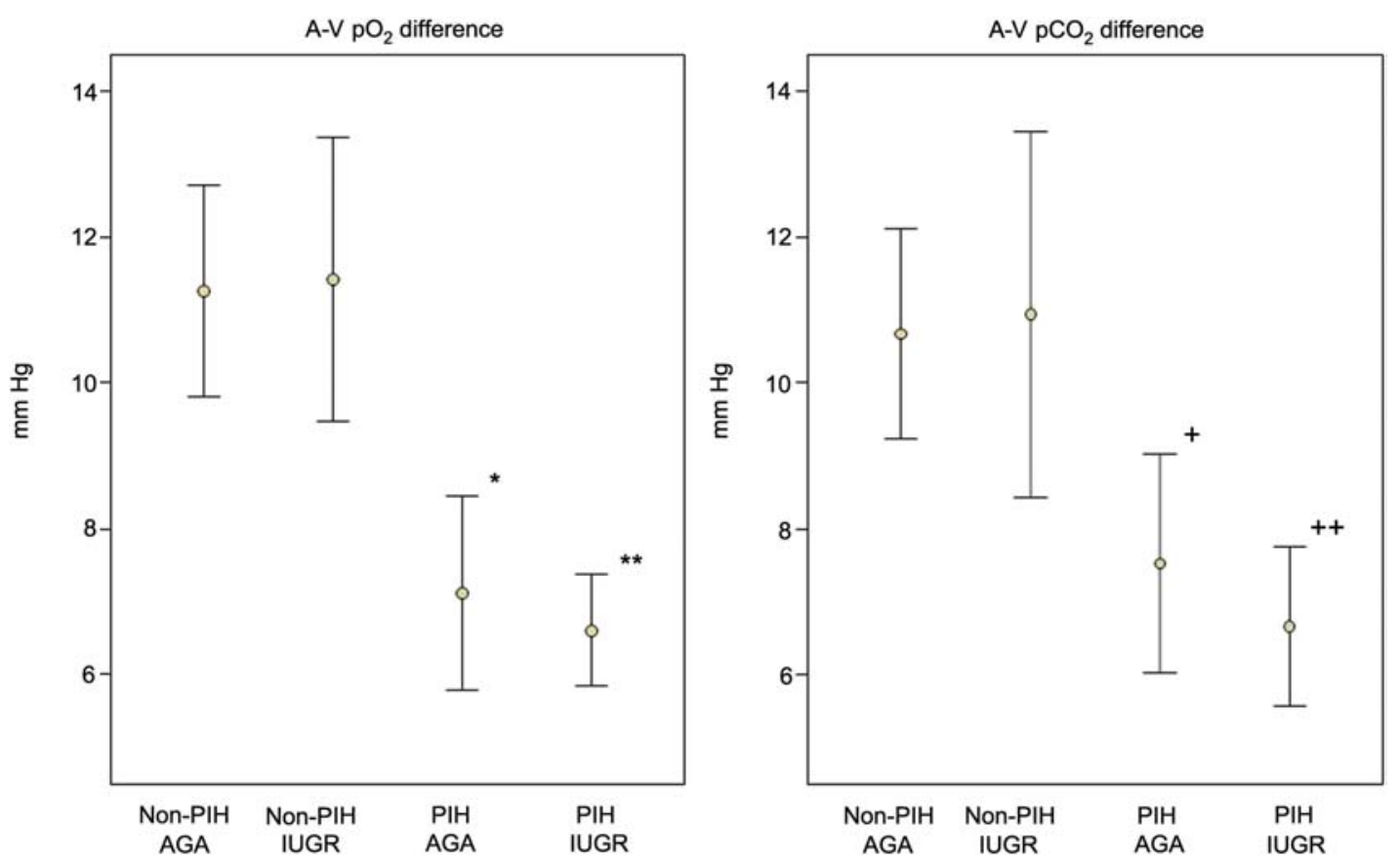

Figure 4 Pre-eclampsia and arteriovenous $\mathrm{pO}_{2}$ and $\mathrm{pCO}_{2}$ difference. Pre-eclampsia decreases placental gas exchange capacity. $\mathrm{PIH}=$ pre-eclampsia; $\mathrm{AGA}=$ appropriate-for-gestational-age; IUGR $=$ intrauterine growth retardation. ${ }^{*} \mathrm{P}=0.001$ (compared to non-PIH AGA), ${ }^{\star \star} P<0.001$ (compared to non-PIH FGR), $+P=0.01$ (compared to non-PIH AGA), $++P=0.044$ (compared to non-PIH FGR).

\section{Discussion}

Umbilical arterial-venous gas difference was recently described to evaluate the placental respiratory function [9]. Placental oxygenation capacity remained steady through pregnancy [9]. This new approach of placental respiratory function was applied in this study to evaluate the effects of placental dysfunction using pre-eclampsia and FGR as models of abnormal placentation in the maternal and fetal compartments, respectively.

Our results suggest that pre-eclampsia is associated with decreased placental gas exchange capacity irrespective of the fetal growth pattern. Surprisingly, similar placental gas exchange capacity was observed between AGA and FGR fetuses in pre-eclamptic women. Several observations require further elaboration.

Pre-eclampsia decreases placental gas exchange. This is consistent with the shallow placentataion theory as a pathophysiologic basis of pre-eclampsia [4, 6, 7, 13]. With normal placentation, the cytotrophoblast invades into the maternal spiral artery within the endometrium to obtain higher oxygen content. With the invasion of the trophoblast, the spiral arteries are transformed from high resistance vessels into larger vessels with low resistance. This vessel remodeling is completed by 18-20 weeks of gestation [4, 13]. Trophoblast differentiation is normal under normal arterial oxygen tension, but continues proliferating under low oxygen tension [3]. Abnormal trophoblast invasion of the spiral arteries, such as in preeclampsia, leads to hypoxic trophoblast cells. Hypoxic stress alters placental villous angiogenesis, which leads to a poorly developed fetoplacental vasculature $[5,11]$. The transfer of oxygen from mother to fetus is limited by blood-flow through the intervillous space [8]. Thus, in pre-eclampsia, the suboptimal placental nutrition and oxygenation predisposes to placental insufficiency and inadequate uteroplacental perfusion [2, 14].

Whether the decreased gas exchange is the chronic in-utero manifestation in pre-eclampsia or is the terminal phenomenon secondary to placental inflammation such as neutrophil accumulation and activation needs further investigation. Increased placental anti-angiogenic factors far prior to the clinically evident pre-eclampsia [6] or increased neutrophil distribution in placentation phase of pre-eclampsia [10] may suggest that the decreased placental gas exchange may be the long-term in utero event seen in pre-clinical stages of pre-eclampsia.

FGR is one of the severe clinical complications of preeclampsia. Decreased oxygen availability is reported as the cause of FGR [12]. Thus, FGR with pre-eclampsia increases the risk for decreased oxygenation capacity compared to FGR in non-pre-eclamptics. Interestingly, pre-eclamptic FGR pregnancies showed lower umbilical $\mathrm{A}-\mathrm{V} \mathrm{pO}_{2}$ differences and lower umbilical venous oxygen tension than non-pre-eclamptic FGR pregnancies (Table 2), without difference in umbilical arterial oxygen tension in both groups. This implies that the placenta of preeclamptic FGR pregnancies has lower oxygenation capacity than non-pre-eclamptic FGR, and thus the umbilical venous return supplies lower oxygen tension to the fetus potentially contributing to the genesis of FGR. Decreased placental oxygenation capacity is character- 
istic of the FGR in pre-eclampsia. However, to our surprise, A-V $\mathrm{pO}_{2}$ difference between pre-eclampsia with AGA fetus and pre-eclampsia with FGR fetus seems similar (Figure 4). This is possibly explained by delivery prior to clinical deterioration of the fetal condition or for maternal indications irrespective of fetal status. In either case, fetal acid-base status may not yet have been affected. Further study into the rate of clinical progression of pre-eclamptic and non-pre-eclamptic FGR pregnancies is necessary to clarify these observations.

It is possible that more pre-eclamptic women were delivered by cesarean section under general anesthesia than non-pre-eclamptic women, where regional anesthesia was more frequently used. Our results showed that there was no statistical difference in the proportions of type of anesthesia between pre-eclampsia and non-preeclampsia in both appropriately-grown and growth restricted fetuses. We previously investigated umbilical arterio-venous cord blood gas difference in uncomplicated spontaneous vaginal and non-labor cesarean section [9]. The values of arterio-venous gas differences among cesarean delivery in that study are similar to our result from non-pre-eclamptic growth restricted cases [9]. Although our results were unaffected by the type of anesthesia, it is generally recognized that the type of anesthesia such as general anesthesia at the time of delivery may interfere with the values of umbilical cord blood gases [15]. Therefore, it is potentially explained that our findings may be due to the short-term effect of type of anesthesia. Our study was limited in the sample size and further studies are needed.

The exact mechanism for the difference in placental gas transfer differences between pre-eclamptic and normal women cannot be determined by this study. We can postulate that diffusion distance between the intervillous space and the fetal villous vasculature is increased, perhaps due to increased interstitial edema. Since oxygen is far more prone to diffusion defects, this can explain the decreased arteriovenous oxygen difference. Alternatively, pre-eclamptic women may have villous occlusive disease in the absence of umbilical artery Doppler abnormalities. These could lead to placental perfusion abnormalities as the main cause of altered oxygen capacity. In the absence of correlation with placental ultrastructure evaluation these questions cannot be addressed by this study and certainly open the possibility for further research.

While there were enough cases to do a one-to-one match between pre-eclamptic FGR and non-pre-eclamptic FGR (114 vs. 80 cases, respectively), there were not enough cases to do a one-to-one match between the two groups of AGA (non-pre-eclamptic AGA vs. preeclamptic AGA, 138 vs. 47 cases, respectively). In order to maximize the chance to reflect the crude data values of the cases, we decided to perform a one-to-two match in the study.

In conclusion, umbilical arterial-venous cord blood gas difference, a novel index of placental respiratory func- tion, was successfully applied to pre-eclampsia, demonstrated that pre-eclamptic FGR is significantly associated with a decreased placental oxygenation capacity. This useful placental respiratory function test requires further investigation in various pathologic conditions during pregnancy.

\section{References}

[1] Bernstein I, Gabbe SG, Reed KL. Intrauterine growth restriction. In: Gabbe SG, Niebyl JR, Simpson JL, editors. Obstetrics: Normal and Problem Pregnancies, 4th ed. New York: Churchill Livingstone; 2002. pp. 607-50.

[2] Brosens IA, Robertson WB, Dixon HG. The role of the spiral arteries in the pathogenesis of preeclampsia. Obstet Gynecol Annu. 1972;1:177-91.

[3] Genbacev O, Zhou Y, Ludlow JW, Fisher SJ. Regulation of human placental development by oxygen tension. Science. 1997;277:1669-72.

[4] Gerretsen G, Huisjes HJ, Elema JD. Morphological changes of the spiral arteries in the placental bed in relation to pre-eclampsia and fetal growth retardation. $\mathrm{Br} \mathrm{J}$ Obstet Gynaecol. 1981;88:876-81.

[5] Kingdom JC, Kaufmann P. Oxygen and placental vascular development. Adv Exp Med Biol. 1999;474:259-75.

[6] Levine RJ, Maynard SE, Qian C, Lim KH, England LJ, Yu $\mathrm{KF}$, et al. Circulating angiogenic factors and the risk of preeclampsia. N Engl J Med. 2004;35:672-83.

[7] Levine RJ, Thadhani R, Qian C, Lam C, Lim KH, Yu KF, et al. Urinary placental growth factor and risk of preeclampsia. J Am Med Assoc. 2005;293:77-85.

[8] Longo LD. Respiration in the fetal-placental unit. In: Cowett RM, editor. Principles of Perinatal-Neonatal Metabolism. New York: Springer-Verlag; 1991. p. 304.

[9] Matsuo K, Malinow AM, Harman CR, Baschat AA. Umbilical arterio-venous gas difference as a novel index of placental respiratory function. Am J Perinatol. 2009;26: 199-206.

[10] Matsuo K, Ushioda N, Harman CR, Kimura T. Increased leukocyte distribution in the pre-clinical stage of preeclampsia. Int J Gynaecol Obstet. 2007;96:31-2.

[11] Myatt L. Role of placenta in preeclampsia. Endocrine. 2002;19:103-11.

[12] Resnik R. Intrauterine growth restriction. Obstet Gynecol. 2002;99:490-6.

[13] Robertson WB, Brosens I, Dixon HG. The pathological response of the vessels of the placental bed to hypertensive pregnancy. J Pathol Bacteriol. 1967;93:581-92.

[14] Robertson WB, Brosens IA, Dixon HG. Placental bed vessels. Am J Obstet Gynecol. 1973;117:294-5.

[15] Reynolds F, Seed PT. Anaesthesia for Caesarean section and neonatal acid-base status: a meta-analysis. Anaesthesia. 2005;60:636-53.

[16] Sibai BM. Hypertension. In: Gabbe SG, Niebyl JR, Simpson JL, editors. Obstetrics: Normal and Problem Pregnancies, 4th ed. New York: Churchill Livingstone; 2002. pp. 945-1004.

The authors stated that there are no conflicts of interest regarding the publication of this article.

Received December 22, 2008. Revised May 4, 2009. Accepted June 2, 2009. Previously published online August 13, 2009. 